\title{
European Legislation and Implementation Measures in the Management of Construction and Demolition Waste
}

\author{
Paola Villoria Sáez**,1 , Mercedes del Río Merino ${ }^{1}$, César Porras Amores ${ }^{2}$ and Alicia de San Antonio \\ González ${ }^{2}$ \\ ${ }^{1}$ Building Technology and Environment (TEMA) Reseach Group, Spain \\ ${ }^{2}$ Polytechnic University of Madrid. School of Building Engineering, Spain
}

\begin{abstract}
The intense activity in the construction sector during the last decade has generated huge volumes of construction and demolition (C\&D) waste. In average, Europe has generated around 890 million tonnes of construction and demolition waste per year.

Although now the activity has entered in a phase of decline, due to the change of the economic cycle, we don't have to forget all the problems caused by such waste, or rather, by their management which is still far from achieving the overall target of 70\% for C\&D waste --excludes soil and stones not containing dangerous substances-- should be recycled in the EU Countries by 2020 (Waste Framework Directive).

But in fact, the reality is that only $50 \%$ of the C\&D waste generated in EU is recycled and $40 \%$ of it corresponds to the recycling of soil and stones not containing dangerous substances.

Aware of this situation, the European Countries are implementing national policies as well as different measures to prevent the waste that can be avoidable and to promote measures to increase recycling and recovering.

In this aspect, this article gives an overview of the amount of C\&D waste generated in European countries, as well as the amount of this waste that is being recycled and the different measures that European countries have applied to solve this situation.
\end{abstract}

Keywords: Construction and demolition waste, Europe, Legislation, Waste management, Generation rate.

\section{INTRODUCTION}

In most European countries there was an increase in the generation of construction and demolition waste during the 1990s. During this decade, Europe generally experienced increased generation of construction and demolition (C\&D) waste [1].

Until today, no official information on generation and composition of the C\&D waste has been found for all of the EU members. The Waste Statistic Regulation [2] provides information on generation and composition of construction and demolition waste in 2006 and in 2008, just for several countries.

Moreover, in 2006 the industry and the construction sectors generated the highest volume of waste, together accounting for $81 \%$ of all waste produced by economic activities [2].

Therefore, the waste stream from the construction was identified as a priority waste stream by the European Union, as it constitutes one of the largest waste streams, since it represents approximately $49 \%$ of the total waste generation in the EU. This represents 887 million tonnes of construction and demolition waste generated in the EU in the year 2008 [2].

*Address correspondence to this author at the Polytechnic University of Madrid. School of Building Engineering, Spain; Tel: 0034 913367607;

Fax: 0034 913367644; E-mail: paola.villoria@upm.es
The C\&D waste, generated by the European countries include a wide range of materials, mostly inert such as: excavation materials, road construction and maintenance materials, but also can contain hazardous waste types such as asbestos, etc. which can be present in significant proportions when buildings are demolished or renovated.

The generation per capita in the old EU Member States and Norway varies significantly. France and Luxembourg generate 5.5 and 15 tonnes per year respectively. Germany and Ireland generate between 2 to 4 tonnes, whereas the rest of the countries generate between 0.2 tonnes (Norway) and 1.9 tonnes (United Kingdom) per capita [3].

All countries where data for more than one year is available except Germany have seen an increase in generation per capita in the period 1995 to 2005.

Normally, data on different waste streams are generally available. However, there are large variations in data quality and reference years [4]. In particular, these differences between countries in generation of construction and demolition waste per capita are very high.

It can be assumed that the differences in the amount of waste from construction and demolition activities derive from the:

- Differences in building tradition. 
- Poor quality of available data. The data do not provide an accurate indication of $C \& D$ waste generation.

- Economic activity within the sector.

- Unequal levels of control and reporting of $C \& D$ waste in Member States.

- Differences in definitions.

Moreover, in an attempt to correct the serious effects which the C\&D waste produce on the environment, important developments have been incorporated into European and International laws, which aims to promote the culture of reuse and recycling.

\section{WASTE MANAGEMENT LEGISLATION IN THE EU}

Waste management legislation is based on European law, all Member States of the EU and of the European Economic Area (Iceland, Liechtenstein and Norway) are bounded by the principles and targets introduced by EU waste legislation.

In the EU there are several directives regarding waste, which have evolved over the last 20 years [5]. In general, these policies must be transposed to the national laws of each country and the Member States should be responsible for carrying out the waste management, which follows the principles of the waste hierarchy.

Environmental protection, and thus by definition also waste legislation, is one of the core concerns within the European Union (EU). Regarding waste, it is reasonable to differentiate between two different periods; the years before and the years after 1990. [3]

The EU legislation on waste from 1975 to 1990 was dominated by administrative requirements (Member States must make waste management plans; EU has to establish a European Waste Catalogue and Member States have to transpose it.). Before 1990 no binding obligation on how to treat waste was introduced by the EU apart from refining waste oil.

However, the period from 1990 to 2008 has been characterised by the introduction of a huge range of recycling initiatives and targets in different directives: The Packaging and Packaging Waste Directive (1994, 2004) [6] [7], the End of Life Vehicles Directive (2000) [8], the Waste Electrical and Electronic Equipment Directive (2002) [9], the Thematic Strategy on the Prevention and Recycling of Waste (2005) [10], the Batteries and Accumulators and Waste Batteries and Accumulators Directive (2006) [11] and the Waste Framework Directive (WFD) targeting construction and demolition waste and waste from households (2008) [12].

Even before the EU initiatives, some Member States had already taken national initiatives in order to increase recycling, although most of the countries were inspired primarily by the initiatives taken by the EU.

In the last couple of years there has been an ongoing discussion of future recycling levels in waste management in the EU. In June 2008 the European Parliament and the Council of the European Union agreed on new recycling targets for construction and demolition waste. The agreement is part of the new WFD which tries to move forward to a European recycling society and is considered one of the pivotal European Directives. This directive regulates general aspects of European waste legislation and, as well as defining the term "waste" and outlining waste management measures and the obligations incumbent upon the originators and proprietors of waste, it also contains the general obligation for Member States to avoid waste and to recover and dispose of it in an environmentally compatible manner.

The WFD states the following target for C\&D waste: "By 2020 the preparing for re-use, recycling and other material recovery, including backfilling operations using waste to substitute other materials, of non-hazardous construction and demolition waste excluding naturally occurring material defined in category 170504 in the European Waste Catalogue (EWC) [13] shall be increased to a minimum of $70 \%$ by weight."

It should be noted that the WFD does not include targets for individual waste types belonging to $\mathrm{C} \& \mathrm{D}$ waste, but does demand an overall target of $70 \%$.

The incorporation of any Directive regarding C\&D waste, into the national law of a country, must take into account several aspects, such as: cost of natural aggregates, landfill space, awareness of the population, stakeholders and cost disposal, among others. Due to the social and political differences in each country, they have developed specific policies or regulations regarding the management of $C \& D$ waste.

The following measures are used by the EU/EEA countries to reduce de $\mathrm{C} \& \mathrm{D}$ waste generated:

\subsection{Landfill Regulations}

A stricter control of landfilling, for certain waste types of C\&D waste, represents a major driver towards better management. For example, in Denmark, it is forbidden the disposal in landfills of the waste that can be incinerated, as well as in the Netherlands or Germany, the disposal of waste that can be recycled. In addition, Denmark has a landfill disposal fee and a voluntary agreement with good practices and environmental management systems for demolition activities. [14].

By the other hand, the Netherlands have a high rate of landfill disposal (approximately $83 € /$ t) compared with other countries like Spain which the average rate of admission is around $12 € / \mathrm{t}$.

\subsection{Waste Management Policy}

Environmental policy should be based on: the precautionary principle, the polluter pays principle and the principle of co-operation. The producer of waste (polluter) is required to consider the environmental impacts and possible risks occurred during his activity, in collaboration with the other parts involved (producers, distributors, consumers, disposal and recycling companies, as well as government offices).

The producer should develop a system which minimizes the adverse environmental impacts and maximizes the recovery of resources (recycling, reuse). For that reason, the implementation of a waste management policy with not only 
economic instruments (taxes on landfill), but legal measures such as: demolishing selectively obligation, voluntary agreements and responsibilities. In this way, even during the production phase, the foundations are laid for the effective and environmentally compatible avoidance and recovery of waste. Manufacturers and distributors must design their products in such a way as to minimize the amount of waste produced during manufacturing and, finally, to facilitate an ecological removal of those components of the waste which can no longer be reused.

This measure is widely used in United Kingdom, Austria or Germany.

Also Spain has implemented a C\&D waste policy with the development of the Second National Plan on C\&D waste in 2008 [15] and the Royal Decree 105/2008 [16]. In this aspect, the construction industry is obligated by law to select and recover some types of C\&D waste if the quantity generated exceeds a certain amount of waste. Austria also applies this measure, but in particular, the Spanish construction companies must segregate individually the different types of waste if they exceed the following amounts: >80t concrete; >40t bricks \& tiles; >2t metal; >1t wood; $>1 \mathrm{t}$ glass, $>0.5 \mathrm{t}$ plastic; $>0.5 \mathrm{t}$ paper.

\subsection{Voluntary Commitment}

The implementation of a national voluntary commitment of the construction industry which aims to reduce $50 \%$ the amount of C\&D waste landfilled, is a measure tried by Germany since 1996 [17], which has given good results.

\subsection{Quality Standards}

The implementation of secondary raw material regulation and standards, for example standards on the quality of secondary materials from C\&D waste. This is the most common measure; it is used in Belgium, Germany and Finland. For example, the Belgium's waste framework policy specifies the nature of the waste which can be used as a secondary raw material in construction as well as the concentrations of heavy metals and aromatic hydrocarbons.

Among the main weaknesses of waste management policies and strategies include those listed below:

- Lack of practices to minimize waste generation.

- Lack of segregation practices on site of the different waste fractions.

- Lack of waste recovery practices.

- Littering. Because of the low cost associated with this alternative, compared to the additional costs of proper waste treatment.

- Lack of knowledge by agents of how to prevent C\&D waste.

- $\quad$ Lack of adequate infrastructure network for treatment. Often, the amount of incoming C\&D waste in plants is still far from its capacity to treat and sometimes have problems with the disposal. Also, the lack of a homogeneous distribution of such infrastructures in the territory generates shortfalls in areas with greater dispersion of population and, conversely, excess processing capacity in relation to the amount of $C \& D$ waste generated in other regions.

\section{RECYCLING OF C\&D WASTE}

\subsection{Recycling Rates of C\&D Waste}

The term "recycling" is difficult to apply consistently to construction and demolition waste across countries as there is a broad range of recycling and recovery activities executed. Recovery can, for a minor part, be incineration with energy recovery, but normally the term recovery is used as "material recovery", for example backfilling operations using waste to substitute other materials.

The $70 \%$ recycling target for C\&DWaste [18] in the new Waste Framework Directive includes "preparing for re-use, recycling and other material recovery including backfilling operations [...]". Further, the definition of recycling explicitly excludes "[...] the reprocessing into materials that are to be used as fuels or for backfilling operations."

In the following, we use the term recycling to mean both recycling and other material recovery as defined in the new Waste Framework Directive.

As seen before, the Waste Statistic Regulation provides information on generation of C\&Dwaste, but it does not provide information about recycling. In general, data about generation, composition and recycling of construction and demolition waste are very limited, particularly regarding its development over time.

In 1990, the Symonds Report [1] is the one of the first, and most popular, report which provides such an overview. This report hold that approximately $40 \%$ of the C\&DWaste produced in European countries were reused or recycled.

To date, "The Recycling Society and its Environmental Effects" is a project which the European Topic Centre on Resource and Waste Management (ETC/RWM), is undertaking in cooperation with the European Environment Agency (EEA). This project identifies the present levels of recycling of different municipal waste streams and construction and demolition waste in the EU Member States and Norway, and their development over the last 10 years.

The current situation in Europe has improved slightly, since the C\&Dwaste recycling averages reach approximately $47 \%$ for EU-27 [19]. Although this average is still far from the goals set in the European Management Plans of C\&DWaste.

The recycling levels for the different waste types are shown in Fig. (1), using a colour scale.

Dark green is indicating a very high rate of recycling and dark red is indicating a very low rate. If no data are available for a country, this is indicated by using a white colour. As seen in Fig. (1), the recycling rate varies significantly among the countries. In general, the rate is approximately $50 \%$ for most countries.

Moreover, Fig. (2) gives more detailed information about recycling rates for a period of years in 18 different countries. 


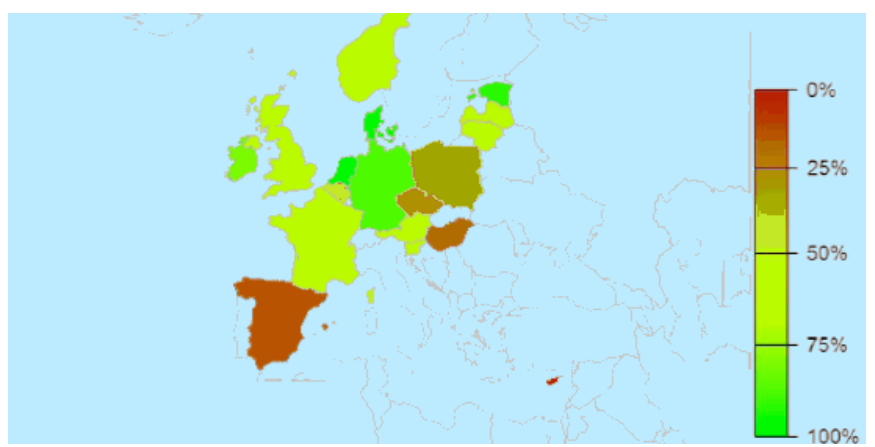

Fig. (1). Recycling rate of construction and demolition waste [5].

It is shown that Denmark, Germany, Ireland, Netherlands and Estonia, fulfill the Directive's target recycling rates, reaching over $80 \%$ of C\&D waste generation, while Austria, Belgium, France, Lithuania and the United Kingdom reaches $60-70 \%$.

Latvia and Lithuania have recycling percentages between $40 \%$ and $60 \%$; although they have very low generation rates.

The southern European countries recycle a very small part of C\&Dwaste. The position of Spain regarding EU countries is not encouraging, even today, continues at the bottom of the list, with Cyprus and Czech Republic which their recycling rate is less than $40 \%$.

During the last years it seems that the recycling level has increased less in countries with already a high level of recycling, than those whose initial level was lower, for example: Czech Republic or Ireland.

The significant differences on the management of C\&Dwaste in each of the EU countries are mainly due to the following reasons:

- The landfill prices are low and the penalties for breach are generally small or they do not exist.

- The raw materials provide sufficient quality at a moderate cost therefore, the recycled materials industry is not well developed in these countries (low-cost of raw materials is a harsh competition with recycled materials).

- The management models used in the EU for the C\&Dwaste differ considerably from one country to another due to different levels of environmental protection. Although some countries have introduced years ago, preventive measures aimed at the recovery of waste, the C\&Dwaste generated by most of them, are

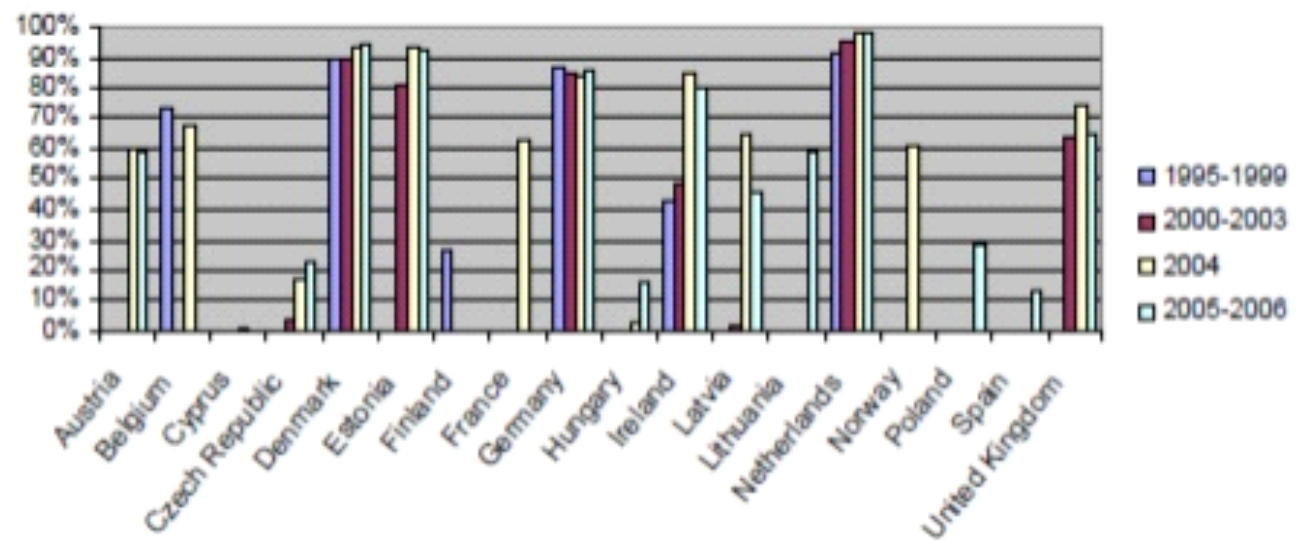

Fig. (2). Recycling of construction and demolition waste in percentage of generated amount in the EU and Norway [3].

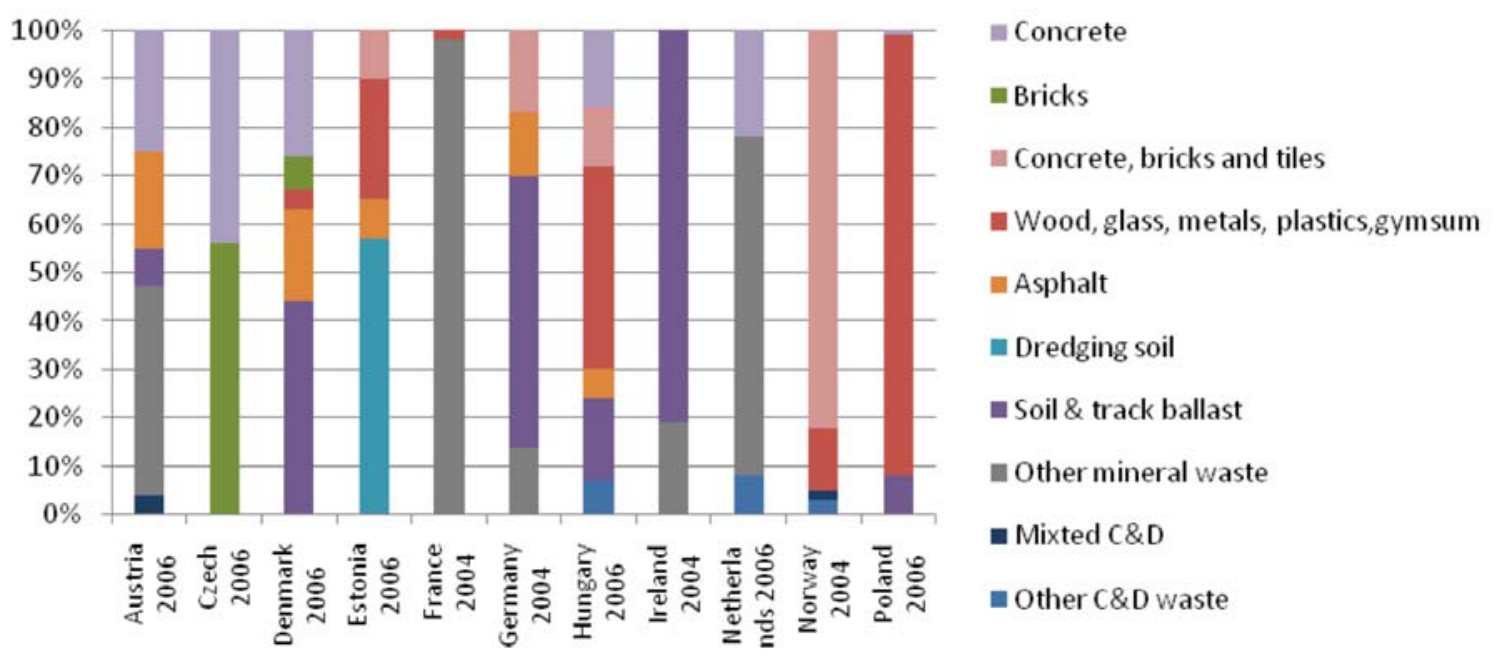

Fig. (3). Percentage composition and development of recycled construction and demolition waste in the EU and Norway. [3]. 
simply dumped in illegal landfills. This illegal disposal is a widespread management for the construction and demolition waste.

- The different regulations in relation to $C \& D W a s t e$ also reveal important differences between EU members. Laws affecting them are not unified, and very few states have specific legislation on C\&Dwaste. However, those countries that have introduced measures to improve its management (Holland, Denmark and Belgium) have achieved high levels of recycling, demonstrating that the C\&DWaste has a strong potential for recycling.

By contrast, countries with high recycling rates, is due to factors such as:

- High prices for the disposal of waste.

- Strong financial incentive by the administrations, when the construction companies separate the waste in different fractions before its disposal.

\subsection{Composition of Recycling of C\&D Waste}

Not all countries have reported data on recycling of $\mathrm{C} \&$ Dwaste to Eurostat. Therefore, it has not been possible to find data for all countries about the composition of recycling of construction and demolition waste. Concrete, bricks, tiles and asphalt are the most commonly recycled construction and demolition waste fractions, but almost all countries with a very high recycling level also recycle a significant quantity of soil.

The very high recycling levels in some countries like for example, Denmark, Germany, Ireland and the Netherlands can possibly be explained by the composition of the recycled waste. Fig. (3) shows the composition of the recycled construction and demolition waste and how it has developed over time.

It is possible to identify recycling of concrete, bricks, tiles and asphalt in all countries with recycling except Ireland and France. Norway and the Czech Republic, has a high portion of recycling of concrete, bricks and tiles, while Austria, Denmark and Germany have a high portion of asphalt.

Denmark, Germany and Ireland have a high rate of soil and track ballast included in the recycling figures. France and the Netherlands have a high rate of other mineral waste included in the recycling figures, whereas Estonia has a high rate of dredging soils.

This indicates that data on C\&D waste does not include the same waste categories in all countries.

Both dredging soil, soil \& track ballast constitute a large part of the recycling. Denmark, Estonia, Germany and Ireland all recycle over $70 \%$ of generated C\&D waste, but a minimum $40 \%$ of the total recycling is by the recycling of dredging soil, soil and track ballast.

The target of $70 \%$ recycling of non-hazardous construction and demolition waste in the new Waste Framework Directive includes backfilling operations but excludes naturally occurring material defined in the category 170504 in the European Waste List (soil and stones not containing dangerous substances). The figures for dredging soil, soil and track ballast shown in Fig. (2) also includes the category 170504, but it has not been possible to isolate the specific amount for each country.

It seems Denmark, Estonia, Germany and Ireland might exhibit a lower level of total recycling in tonnes if category 170504 is excluded. The precise influence of this on the recycled percentage of generated waste is difficult to gauge, since the generated amount of this waste category should also be excluded.

Further, most of the countries with a high total recycling as a percentage of generated waste also have a high amount in tonnes of recycled concrete, asphalt, metals.

\section{CONCLUSIONS}

Construction and demolition waste is a major component of the solid waste stream. Each year, 890.000 .000 tones of C\&D waste is generated in Europe. This waste should be recognised as a valuable resource as large quantities of it could either be recycled or reused.

Moreover, it has been difficult to obtain sufficient and standardize data for all of the countries, especially for the recycling rate. In this sense, an effort towards a homogeneous data in all the EU countries is needed.

In addition, as it has been shown, the generation rate in ton per capita differs among countries, due to the differences in building tradition or the economic activity of the country.

By the other hand, the recycling rate is quite reasonably in percentage ( $>50 \%)$ for most of the countries analysed. Excluding soil and stones without hazardous substances, the waste which comes from concrete, bricks, tiles and asphalt, is the most common waste which is being recycled by most of the EU/EEA members.

Nevertheless, countries with a high percentage of recycling rate of construction and demolition waste take into account the recycling of dredging soil, soil and track ballast, which correspond to a large part of the waste recycled. In this sense, soil is excluded in the new recycling target for C\&D waste, according to the new Waste Framework Directive.

Therefore, we are still far away to reach the recycling target for 2020, we still need to improve national and European legislation, making great efforts to unify the data and definitions, towards the correct management of the $\mathrm{C} \& \mathrm{D}$ waste generated in the construction activity.

\section{ACKNOWLEDGMENTS}

None declared.

\section{CONFLICT OF INTEREST}

None declared.

\section{REFERENCES}

[1] Report by Symonds, in association with ARGUS, COWI and PRC Bouwcentru "Construction and demolition waste management practices, and their economic impacts", Final Report to DGXI, European Commission, 1999.

[2] Statistical Office of the European Communities (EUROSTAT) 2011. Statics Database. http://epp.eurostat.ec.europa.eu/portal/ page/portal/statistics/search_database [Accessed: 05/01/2011]. 
[3] R. Almut, C. Fischer, and M. Werge, "EU as a Recycling Society. Present recycling levels of Municipal Waste and Construction \& Demolition Waste in the EU", ETC/SCP working paper 2/2009. European Topic Centre on Sustainable Consumption and Production (ETC/SCP). Copenhagen. Denmark, 2008.

[4] D. Tsotsos, J. Brodersen, J. Juul, and H. Jacobsen, "Review of selected waste streams: Sewage sludge, construction and demolition waste, waste oils, waste from coal-fired power plants and biodegradable municipal waste", European Topic Centre on Waste and European Environment Agency. Copenhagen, 2002.

[5] European Commission, "The story behind the strategy. EU Waste Policy." http://ec.europa.eu/environment/waste/pdf/story_book.pdf [Accessed: 05/01/2011].

[6] Directive 94/62/EC of 20 December 1994 on packaging and packaging waste.

[7] Directive 2005/20/EC of the European Parliament and of the Council of 9 March 2005 amending Directive 94/62/EC on packaging and packaging waste

[8] Directive 2000/53/EC of the European Parliament and of the Council of 18 September 2000 on end-of life vehicles.

[9] European Community directive 2002/96/EC on waste electrical and electronic equipment (WEEE)
[10] Thematic Strategy on the Prevention and Recycling of Waste (2005)

[11] Directive 2006/66/EC on batteries and accumulators and waste batteries and accumulators (2006)

[12] European Directive 2008/98/EC. Waste Framework Directive targeting construction and demolition waste and waste from households (2008)

[13] Commission Decision 2000/532/EC. 2000. European List of Waste

[14] $4^{\text {th }}$ National congress for demolition and recycling. Zaragoza, Spain. [Accessed: May 2009].

[15] Gobierno de España. Plan Nacional Integrado de Residuos para el Período 2008-2015. España. Ministerio de Medio Ambiente, y Medio Rural y Marino, 2009.

[16] Ral Decree 105/2008. Ministerio de Medio Ambiente y Medio Rural y Marino, 2008.

[17] Fedeoyral Ministry for the Environment, Nature Conservation and Nuclear Safety (BMU). 2006 "Waste management in Germany. A driving force for jobs and innovation". Berlin, Germany.

[18] European Environment Agency. 2010. "The European environment. State and outlook 2010. Material resources and waste." Publications Office of the European Union. Luxembourg

[19] Bio Intelligence Service. Web: http://biois.com/sign/test/scp.htm . [Accessed: 04/01/2011].

Received: October 11, 2011

Revised: October 22, 2011

Accepted: October 25, 2011

(c) Villoria Sáez et al.; Licensee Bentham Open.

This is an open access article licensed under the terms of the Creative Commons Attribution Non-Commercial License (http://creativecommons.org/licenses/by-nc/3.0/) which permits unrestricted, non-commercial use, distribution and reproduction in any medium, provided the work is properly cited. 